\section{Crusted scabies in systemic lupus erythematosus: More than a mite contagious case}

Eva Lydiawati, Indropo Agusni, Dwi Murtiastutik, Evy Ervianti, Sawitri, Trisiswati Indranarum, Septiana Widyantari, Hasnikmah Mappamasing

Department of Dermatology and Venereology, Universitas Airlangga, Dr. Soetomo General Hospital, Surabaya, Indonesia

\begin{abstract}
Crusted scabies is characterized by hyperkeratosis and crusting of the skin due to the profuse proliferation of mites. It is resulting from an altered host response to the infestation. There are some various cutaneous and immunologic diseases that have been described to predispose to crusted scabies. It is typically associated with congenital and acquired immunocompromised conditions including human immunodeficiency virus (HIV), hematologic malignancy, and connective tissue diseases, including systemic lupus erythematosus (SLE). Adults with crusted scabies may lack the characteristic rash or itching. Sites of presentation have been reported on the scalp, face, neck, extremities, trunk, hands, and feet. The severe condition of SLE and super infection of scabies in the immunocompromised state highlight the need for appropriate care to avoid further morbidity. This case report aims to describe the characteristic of skin lesions and clinical aspects of crusted scabies in SLE. A 28-year-old man was diagnosed with crusted scabies who was treated more intensely with permethrin 5\% cream that was combined with 2-4 ointment. There was clinical improvement and no side effect found during this study.
\end{abstract}

\section{Introduction}

Scabies is a contagious skin infestation caused by the penetration of the obligate human parasitic mite Sacrcoptes scabiei var hominis into the epidermis. Animal scabies such as canine sarcoptic mange or feline mange may afflict humans. It may manifests as a pruritic dermatosis with excoriation and crusting. However, it is considered to be uncommon because of the relative host specificity of the mites. ${ }^{1}$

Crusted scabies is a rare, atypical, and highly infectious variant of Sarcoptes scabiei. Clinically, this condition visually pres- ents as a dermatitis and causes extensive hyperkeratotic lesions, nail thickening, and dystrophy. ${ }^{2}$ Crusted scabies typically presents as a psoriasiform hyperkeratotic dermatosis of the hands, feet, nails, face, neck, scalp, and trunk. It is typically associated with several congenital and acquired immunocompromised conditions including human immunodeficiency virus (HIV), hematologic malignancy, neurologic illnesses, and connective tissue diseases, including systemic lupus erythematosus or SLE. ${ }^{3}$ So that, this case report aims to describe the clinical aspects and the therapy of crusted scabies in SLE patient.

\section{Case Report}

A 28-year-old man was referred to our hospital in August 2017 with a thick crust in almost all over his body since 2 months ago. It was also accompanied with rash at his hand and mild itchy sensation. He complained those itchy rash became worse at night and whe he got sweat. The rash sreaded to all over his body and became thickened with crust but without any pain sensation. Patient was hospitalized in Dr. Soetomo General Hospital because of his stomach that become bigger and accompanied with general weakness. He has a history of recurrent anemia, photosensitivity, and oral ulcer before.

His wife and brother also got the same complaint but less severe than him. There were no history of suffering from such disease before. History of applying any topical ointment for his rash about 3 days before hospitalization. History of taking any traditional medicine before was denied. There were no history of food or drug allergy.

Physical examination on regio generalisata expecially on abdomen, forearm and hands, we discovered hyperpigmented macules unsharply marginated and covered by thick crusts. In addition, there was also erosion and multipel erythematous papules around them. We did not find any pustules. The initial presentation of this disease could be seen on Figure 1 (A-C).

From laboratory examination we found that the hemoglobin was decreased $(5,1$ $\mathrm{g} / \mathrm{dL}$ ) and leucopenia (white blood cell + $3,48.10^{3} / \mu \mathrm{L}$ ), thrombocytopenia (thrombocyte $=47.000 / / \mu \mathrm{L})$, and hypoalbuminemia (albumin $=1,9 \mathrm{~g} / \mathrm{dL}$ ). The HIV rapid test was performed and showed non-reactivity in him. ANA titer was 1:64, and he was then diagnosed with systemic lupus erythematosus.

We did performed skin scraping on the area of thickened crust (on his hands). From this examination we found the mites of
Correspondence: Eva Lydiawati, Department of Dermatology and Venereology, Faculty of Medicine, Universitas Airlangga/Dr. Soetomo General Hospital, Prof Dr Moestopo 47, Surabaya, Indonesia.

Tel.: +6281334555885.

E-mail: evalydiawati@gmail.com

Key words: crusted scabies, systemic lupus erythematosus, Sarcoptes scabiei.

Acknowledgements: The authors would like to express their genuine thanks to the Dermatovenereology Ward and Outpatient's Clinic of Dr. Soetomo General Hospital Surabaya and patient who participated in this study.

Contributions: EL, IA, data collecting and analyzing; EL, manuscript writing; EL, IA, DW, EE, S, TI, SW, HM, manuscript reviewing and references search.

Conflict of interests: The authors declare no potential conflict of interest.

Received for publication: 1 February 2019. Accepted for publication: 22 February 2019.

This work is licensed under a Creative Commons Attribution-NonCommercial 4.0 International License (CC BY-NC 4.0).

(C) Copyright E. Lydiawati et al., 2019

Licensee PAGEPress, Italy

Dermatology Reports 2019; 11(s1):8085

doi:10.4081/dr.2019.8085

Sarcoptes scabiei in the nymph and adult phase. Not only that, but also its eggs and scybala. This examination observed by using microscope and could be clearly seen in Figure 2 (A-D) below. These findings indicate that it might be abundant mites that live underneath his skin and crusts. This examination was the gold standart of the diagnosis of scabies in this patient.

Based on theses findings, from physical and laboratory examination, he was diagnosed with crusted scabies with systemic lupus erythematosus. He also have pancytopenia (anemia, leucopenia, and thrombocytopenia) and hypoalbuminemia.

We treated the patient with Permethrin $5 \%$ cream twice a week in all over his body. It was combined with $2-4$ ointment (combination of Sulfur precipitate and salicylic acid in Indonesia) that was used by him twice a day on the lesions only. We added the treatment with chlorpheniramin maleate tablets and optimize the therapy of SLE itself. There was clinical improvement of the lesions after 2 weeks of treatment. We can see it in the Figure 2 (D and E) above. The hyperpigmented macules still persist 
but scales diminished obviously on the patient.

\section{Discussion}

The ancestral origin of the scabies mite, Sarcoptes scabiei, that parasitizes humans and many families of mammals is not recognized. Similarly, how long ago the coevolution of those mites with specific host mammals began and how this has evolved over time is still undetermined. However, acarologists and mammalogists using molecular tools and genomic information may clarify these questions in time. ${ }^{4}$

Human scabies is characterized clinically by pruritus with nocturnal exacerbation and contagiousness. Not only that, but also the scabietic nodules as well as visible skin burrows can be the pathognomonic lesions of scabies. Under normal circumstances, the diagnosis can be readily made by the clinical distribution, appearance of skin lesions and clinical history. However, scabies can present with an atypical clinical pattern in some certain situations, including patients on prolonged steroid therapy, immunocompromised condition and nodular scabies. ${ }^{1}$

Crusted scabies was firstly described by Boeck and Danielssen among lepers in Norway in 1848. It was named as "Scabies Norvegi Boeki" by von Hebra in 1862 . This severe variant of scabies occurs as widespread hyperkeratotic crusted lesions and later the name "crusted scabies" is preferred to the eponym of "Norwegian scabies". 5

Crusted scabies is characterized by hyperkeratosis and crusting of the skin due to the profuse proliferation of mites resulting from an altered host response to the infestation. Various cutaneous, neurologic and immunologic diseases have been described to predispose to crusted scabies. It is typically associated with several congenital and acquired immunocompromised conditions including human immunodeficiency virus (HIV), hematologic malignancy, neurologic illnesses, and connective tissue diseases, including systemic lupus erythematosus or SLE. ${ }^{2}$

Unlike typical scabies, adults with crusted scabies may lack the characteristic rash or itching. Sites of presentation have been reported on the scalp, face, neck, extremities, trunk, hands, and feet..$^{5}$ These hyperkeratotic plaques can carry up to 4000 mites per gram of skin compared to about 20 mites on the entire skin of individuals with ordinary scabies. ${ }^{3}$ This hyper-infestation can lead to institutional outbreaks. Additionally, these plaques are known to slough off and cause fissuring, which predisposes to secondary bacterial infections associated with sepsis and higher mortality.

The most severe form, crusted scabies, is often reported to occur in hosts who are immunodeficient or immunosuppressed condition. This is further emphasizing the importance of the immune system in the clinical manifestation of the disease. The immunologic defect in crusted scabies has been attributed to deficient cell-mediated immunity or to combined humoral and cellmediated immune deficiency. ${ }^{5}$

In SLE, the immune system taught to be defective in so many ways. The leukocytes show functional abnormalities, such as defective phagocytosis, and decreased leukocyte chemotaxis. Cellular immunity is depressed too as is selective humoral response to certain external antigens. It will be the trigger to make the scabies in SLE more severe and florid than usual.

The number of CD4+ was generally found to be lower in patients with SLE as compared with healthy individuals. So that the symptoms of pruritus also lower in crusted scabies in SLE patient. ${ }^{6}$ CD8+ were much more dominant than CD4+ in SLE patient. It is further hypothesized that these CD8+ T lymphocytes might be the cause of keratinocytes apoptosis leading to epidermal hyperproliferation in crusted scabies. ${ }^{7}$

Our patient's primary lesions involvement demonstrates an atypical presentation of crusted scabies, which should be considered in patients who are immunosuppressed. In addition, the patient's severe condition of lupus erythematosus and super infection in his immunocompromised state highlight the need for appropriate care to avoid further morbidity and possible mortality.

Combination treatment including oral ivermectin and topical agents such as permethrin or benzyl benzoate is generally recommended for this highly contagious scabies variant. ${ }^{3,8}$ However, our patient's did not get ivermectin therapy because of its limitation in the drug pharmacy. The clinical condition responded well to the combination of topical treatments by using permethrin 5\% cream and $2-4$ ointment (sulfur precipitate and salicylic acid). An additional goal of treatment would be to lessen any immunosuppression in those patients who may tolerate the therapeutic measurements.
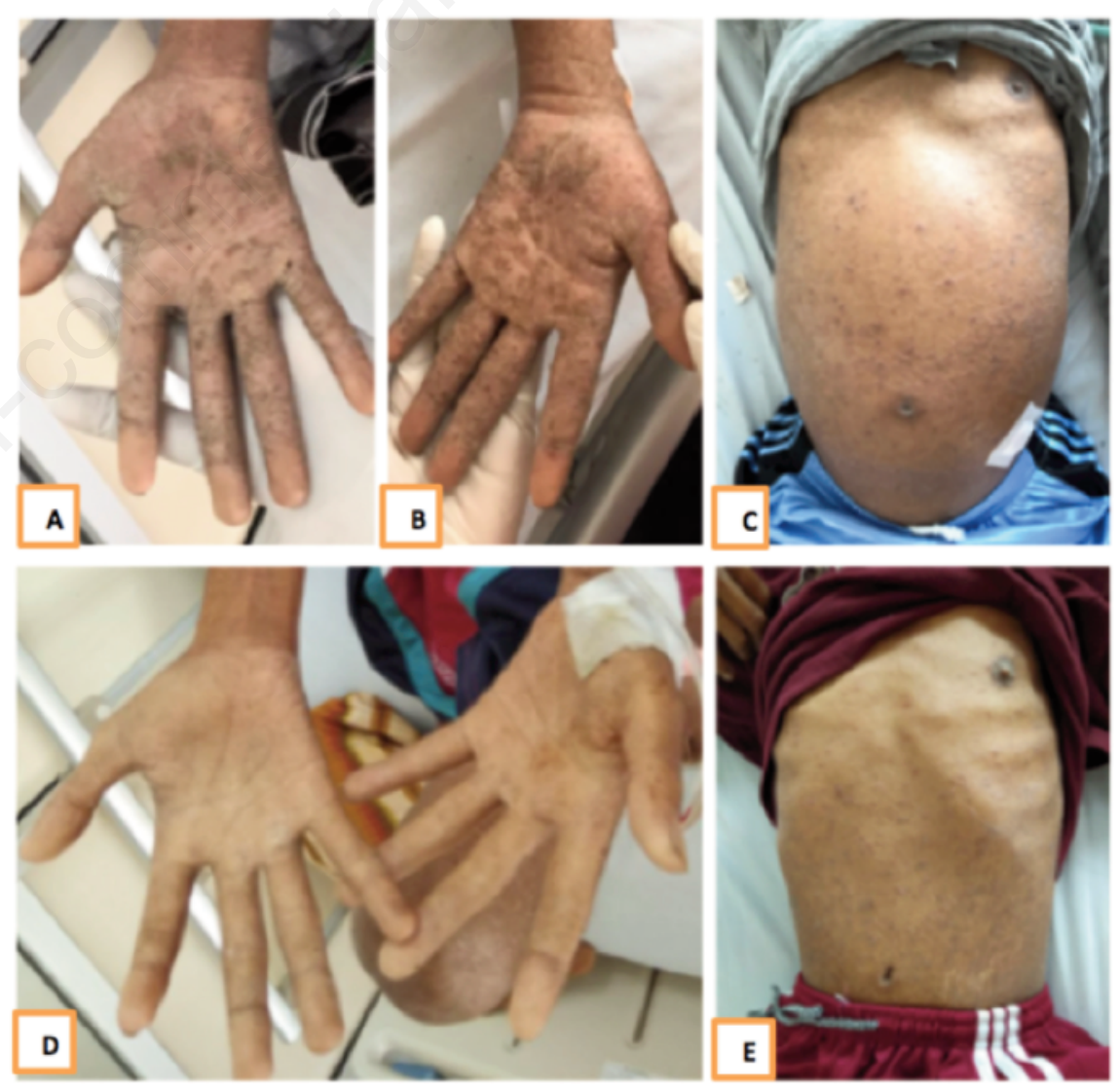

Figure 1. (A-C) The initial presentation of crusted scabies in systemic lupus erythematosus patient. It manifested as erythematous plaques and adherent white yellowish scales on palms and abdomen; (D and E) Clinical improvement of the lesions after 2 weeks of treatment. The hyperpigmented macules still persist but scales diminished obviously. 

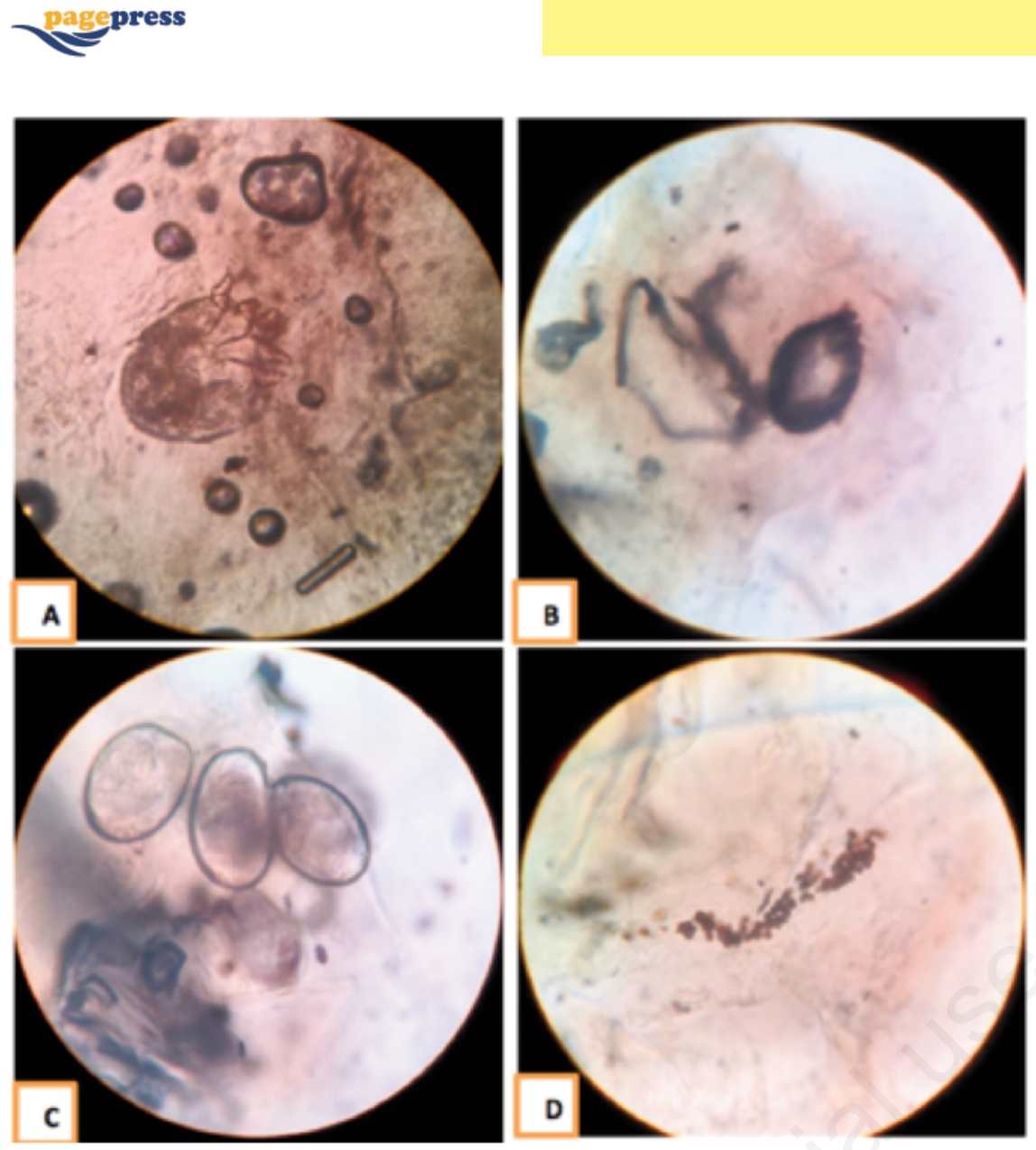

symptoms of them with typical common-

Figure 2. (A and B) Founding the Sarcoptes scabiei mite on skin scrapping; (C) The eggs of Sarcoptes scabiei before it was hatched; (D) The scybala that we found as the predictor of the mite existance.

\section{Conclusions}

Our case highlights the atypical presentation of crusted scabies on the skin of the patient with systemic lupus erythematosus. The distinct manifestation and different symptoms of them with typical common scabies make the diagnosis more challenging. The proper diagnostic tools by taking the history of the disease, physical and laboratory examination, added with skin scrap- ping, will guide us to diagnose this disease properly. After that, we could treat by means of therapy that can be systemic with oral ivermectin (if available), or topical with permethrin cream, or the combination of both. In this case provided significant clinical improvement within one-week of treatment. Medications are generally well tolerated, and early diagnosis and treatment can prevent significant morbidity in this often-misdiagnosed communicable disease.

\section{References}

1. Park JH, Kim CW, Kim SS. The diagnostic accuracy of dermoscopy for scabies. Ann Dermatol 2012;24:194-199.

2. Maghrabi MM, Lum S, Joba AT, et al. Norwegian Crusted Scabies: An Unusual Case Presentation. J Foot Ankle Surg 2014;53:62-66.

3. Yee BE, Carlos CA, Hata T. Crusted scabies of the scalp in a patient with systemic lupus erythematosus. Dermatology Online Journal 2014;20: 1-4.

4. Arlian LG, Morgan MS 2017. A review of Sarcoptes scabiei: past, present and future. Parasit Vectors 2017;10:297.

5. Karthikeyan K. Crusted scabies. Indian J Dermatol Venereol Leprol 2009;75: 340-7.

6. Cava AL. T-regulatory cells in systemic lupus erythematosus. Lupus 2008;17: 421-5.

7. Mak A, Kow NY. The Pathology of T cells in systemic lupus erythematosus. J Immunol Res 2014;1-9.

8. Ortega-Loayza AG, McCall CO, Nunley JR. Crusted scabies and multiple dosages of ivermectin. J Drugs Dermatol 2013;12:584-5. 